\title{
Suicide in Older Adults
}

\author{
Yeates Conwell, MD, \\ Professor of Psychiatry, University of Rochester Medical Center, 300 Crittenden Blvd., Rochester, \\ NY 14642, Phone: 585-275-6739, Fax: 585-273-1066
}

Kimberly Van Orden, PhD, and Instructor, Department of Psychiatry, University of Rochester Medical Center, 300 Crittenden Blvd., Rochester, NY 14642, Phone: 585-275-5176, Fax: 585-273-1066

Eric D. Caine, MD

Professor and John Romano Chair, Department of Psychiatry, University of Rochester Medical Center, 300 Crittenden Blvd., Rochester, NY 14642, Phone: 585-275-3574, Fax: 585-273-1066

Yeates Conwell: yeates_conwell@urmc.rochester.edu; Kimberly Van Orden: kimberly_vanorden@urmc.rochester.edu; Eric D. Caine: eric_caine@urmc.rochester.edu

\section{Keywords}

Suicide; older adult; aged; prevention

\section{Introduction}

\begin{abstract}
Suicide at any age is a tragedy for the individual, his or her family and friends, and the communities of which they are a part. At a population level suicide is also a major public health problem, accounting for over 34,500 deaths each year in the United States (1) and an estimated one million or more worldwide (2). The largest number of suicides occurs in younger and middle-aged adults and suicide deaths in youth and young adults capture the bulk of media attention. In this chapter, however, we make the case that late life suicide is a cause for enormous concern that warrants ongoing attention from researchers, health care providers, policy makers, and society at large. Acknowledging the complexity and multidetermined nature of suicidal behavior in older adults, we provide a framework for its understanding and on which to base its prevention. We review the evidence for factors that place older adults at risk for suicide, or protect them from it. Taken individually, however, risk factors offer relatively weak guidance for implementation of successful suicide prevention initiatives because, at the individual level, their ability to predict who will die by suicide is so poor. We argue then from a public health perspective for understanding suicide as a developmental process to which risk and protective factors contribute in defining a trajectory to suicide over time. Translation of that developmental perspective into preventive interventions next requires identification of opportunities to intervene, the sites or "points of engagement" where older adults can best be detected and interventions made to alter their suicidal trajectories. Finally, we introduce the notion that suicide preventive interventions target individuals or groups at different levels of risk at different points on the developmental trajectory towards death by suicide, offering examples of each and recommendation their strategic, combined application to create an effective, community level response to the mounting problem of suicide in older adults.
\end{abstract}

Correspondence to: Yeates Conwell, yeates_conwell@urmc.rochester.edu.

Financial disclosures: The authors have nothing to disclose. 


\section{The Epidemiology of Suicide in Later Life}

In most countries throughout the world that report such statistics to the World Health Organization, suicide rates tend to rise as a function of age for both men and women to a peak in old, old age (2). There is great variability, however. In Canada, for example, suicide rates peak at mid-life for both men and women and decline slightly thereafter. In recent years the United States has exhibited the same pattern for the overall population. Figure 1, however, shows a more complex picture when rates are considered as a function of age, gender, and race. For both black and white women, rates rise through midlife and fall thereafter; black men experience two peaks of risk, one in young adulthood and the second in old age. Most striking is the higher rate at every point in the life course for white men, rising to a peak in the oldest age group of over 45 per 100,000 per year, over 4 times the nation's overall age adjusted rate of 11.5 per 100,000 per year (1).

There is good news and bad news in trends with regard to aging and suicide over time in the U.S. where, as depicted in Figure 2, the overall rate of suicide fell slowly but steadily from 1985 through 2000, after which it has begun to rise again marginally (1). Reductions in rates among youth, young adults, and those over age 65 largely accounted for the decrease. Indeed, since 1986 rates have dropped among older adults in the United States by over 35 percent, even as suicide rates have risen by almost 20 percent over the last 8 years among those ages 35 to 64 . While the steady reduction in suicide rates among older adults is encouraging, the recent rise in rates by those in the middle years is a cause for serious concern. Birth cohorts tend to carry with them a characteristic propensity to suicide as they age. The "baby boom" cohort, those born between 1946 and 1964, has had relatively higher suicide rates at any given age than earlier or subsequent birth cohorts. As well, the leading edge of the baby boom cohort will reach age 65 in 2011, fueling rapid growth over the next 20 years in the total size of the older adult population. Demographers estimate that by the year 2030 over 71 million United States citizens will be age 65 or older, or 20 percent of the US population (3). Therefore, as the baby boom cohort, a group with historically high rates of suicide, enters older adulthood, the time of greatest risk, in such large numbers, we anticipate that the rate of suicide in men and women will rise again, resulting in substantial increases in the absolute numbers of senior citizens dying by their own hands.

\section{Risk and Protective Factors}

In order to design interventions with the objective of reducing suicide-related morbidity and mortality, we must understand its causes. Establishing causation of a complex, multidetermined, rare and dire outcome such as suicide is a daunting task. However, identification of risk and protective factors can guide our prevention efforts. Much of what we know about factors that place older adults at risk for suicide, or protect them from it, has been learned from retrospective analysis of the characteristics, backgrounds and circumstances of people who kill themselves, an approach known as the psychological autopsy (PA) method (4). Although subject to recall bias and other limitations inherent to retrospective data collection, the PA approach has advantages as well, including a detailed focus on those who die by suicide. It remains unclear how applicable lessons learned from the study of suicidal ideation and attempts in later life are to the understanding of completed suicide. Longitudinal cohort studies in which sufficient numbers die by suicide to allow meaningful analyses are unfeasible because suicide is a relatively rare event. Furthermore, even in longitudinal studies the time between a subject's most recent assessment and death, a critical period for understanding the more immediate precipitants of suicidal behavior, would require retrospective analysis. Reinforced by studies demonstrating the validity of the PA method $(5,6)$, a variety of investigators have applied it in case control studies that provide remarkably consistent findings (7-21). Results indicate that specific factors in 
domains of psychiatric illness, social connectedness of the older person with his or her family, friends, and community, physical illness and functional capacity appear to influence risk for suicide. They in turn operate against a backdrop of individual's culture, personality, and neurobiological milieu. We examine briefly the evidence for each in turn.

\section{Psychiatric illness}

Of all factors examined in PA studies of older adults, psychiatric illness consistently emerges as the most prominent. Table 1 lists rates of psychiatric and substance use disorders reported in samples of older people who died by suicide in a range of studies. Table 2 lists results from PA studies that included a control group, allowing calculation of an odds ratio (OR) reflecting the strength of the association between specific Axis I psychiatric disorders and suicide in the second half of life. The lessons are clear. Psychiatric illness is present in from $71 \%$ to $97 \%$ of suicides, with affective disorder being the most common. In particular, major depression is most closely associated. Primary psychotic disorders including schizophrenia, schizoaffective illness, and delusion disorder, as well as anxiety disorders, tend to be present in lower proportions. The prevalence of substance use disorders was highly variable in these studies, reflecting differences in the measures used, the populations examined, and their socio-cultural context. Rates of problem drinking, for example differ markedly in the East (9) and West (21).

As indicated in Table 2, the odds of an older adult having any Axis I diagnosis were between 44 and 113 times higher for suicides than matched controls. The highest ORs were observed for mood disorders, with lower ORs and generally more mixed results in those studies that examined substance abuse and dependence, schizophrenia, anxiety disorders. The wide variation between studies in the strength of associations observed can also be accounted for by methodologic differences, including the choice of control group. For example, Harwood and colleagues compared completed suicides with controls who died of natural causes in hospital (12), whereas the other listed studies used living community controls. Consequently Harwood et al reported, for example, that the diagnosis of dementia or delirium was significantly less common in suicides than controls, a counterintuitive finding not observed in the other studies and likely explained by high rates of cognitive disorders and confusional states in hospitalized and terminally ill elders. The PA method may be poorly suited to the study of dementia and delirium the signs and symptoms of which, particularly early in the course of illness when the patient may be at relatively greater risk $(22,23)$, are less likely to be apparent in community settings to family members and other proxy informants. Other biological (24) and epidemiologic (22) data provide at least preliminary evidence that dementia too is associated with increased risk of suicide in older adults.

\section{Physical health and functioning}

In addition to psychiatric illness, physical ill health and functional impairments contribute to risk for suicide in later life. Because the base rates of physical illness and disability are so high in this population, however, their usefulness in identifying individual elders who warrant intervention is weak. For instance, record linkage studies have consistently found that individuals with malignancies (other than common skin cancers) are at approximately 2 times greater risk for suicide than those without (25). Other diverse conditions such as HIV/ AIDS, epilepsy, Huntington's disease and multiple sclerosis, renal and peptic ulcer disease, heart and lung diseases, spinal cord injury and systemic lupus erythematosus have also been found to be associated with increased suicide risk in some studies (25-27). Relative risks for suicide associated with these conditions are in the range of 1.5 to 4 times higher. 
Although the relative risk for suicide associated with any specific condition may be small, as the number of an individual's acute and chronic conditions increases, so does his cumulative risk. Juurlink and colleagues linked prescription records of all residents of Ontario, Canada, aged 65 years and older with provincial coroners' reports of suicide in a case control analysis (26). They found that patients with three physical illnesses had approximately a threefold increase in estimated relative risk for suicide compared with subjects who had no diagnosis, whereas older adults who had seven or more illnesses had approximately nine times greater risk for suicide.

Beyond the number of physical illnesses, it is likely that the perceived meaning of those illnesses, their impact on function, pain, and threats to autonomy and personal integrity play pivotal roles as well. For example, in a case controlled comparison of suicides over age 50 years with living demographically matched controls, our group found in multivariate analyses that the presence of any impairment in instrumental activities in daily living (IADLs) was significantly associated with suicide case status independent of the effects of physical and mental health disorder diagnoses (21). Elsewhere we have noted that elderly suicide decedents commonly communicated a belief to others that they had cancer that on autopsy was unconfirmed. Yet there was no other indication of thought disorder or cognitive impairment (28). Perceived health status may ultimately prove to have greater salience to late life suicide and its prevention than objective measures, just as has been observed in association with natural death and all-cause mortality (29).

Although relatively little research has examined associations between pain and suicide in older adults, several studies suggest that it may be an especially important issue among older men. Juurlink and colleagues, for example, reported that the association between severe pain and suicide was somewhat stronger for men $(\mathrm{OR}=9.9)$ than women $(\mathrm{OR}=3.3)(26)$.

Similarly, Sirey and colleagues found a stronger association between suicidal ideation and chronic pain among older adult men receiving home delivered meals than women (30); and in their recent analysis of elderly home care recipients, $\mathrm{Li}$ and Conwell found that men with severe and uncontrolled pain were at especially high risk for self injury ideation, whereas no such association was observed in women (31).

Cognitive deficits in later life have also been linked to suicide. Dombrovski and colleagues, for example, have reported that elderly suicidal depressives performed worse on measures of frontal executive function as well as memory and attention tests than did non-suicidal elderly depressives (32). Frontal executive function may be particularly pertinent to suicidal behavior in older adulthood because of its role in effective management of stressful circumstances. Keilp and colleagues found that adult suicide attempters performed poorly on frontal executive tasks relative to controls (33), a similar observation to one made by King and colleagues in older adult attempters (34). The cognitive mechanisms underlying relationships between cognitive control, problem solving, and suicidal behavior remain obscure. Dombrovski and colleagues examined more specific components of decision making for their association with suicidal behavior in old age, focusing in particular on reward/punishment based learning, abnormalities in which have been related in pathology in ventral prefrontal circuits (35). Their finding of deficits in depressed attempters supports the notion that late life suicidal behavior is in some instances associated with impaired decisionmaking based on impaired ability to access and use prior experience, which in turn may be related to underlying age-related ventral prefrontal pathology (36). Other reports support a link between suicidal behavior in older adults and brain pathology. Ahearn and colleagues, for example, reported that elderly depressives with lifetime histories of suicide attempts had significantly more subcortical gray matter hyperintensities on MRI than carefully matched depressives with no previous suicide attempt history (37), supporting the hypothesis that 
underlying vascular disease may predispose to late life depressive illness and suicidal behavior (38).

\section{Social factors}

PA studies clearly and consistently demonstrate a role for social factors in the pathogenesis, and therefore prevention, of suicide in older adults as well. Two broad categories in this domain warrant special note - stressful life events as predisposing factors and social connectedness as a buffer that serves to reduce suicide risk.

It is clear that stressful life events preceding death by suicide tend to be more numerous and severe among suicides than controls. The events most salient to suicide in later life are those associated with aging - threats associated with ill health and functional impairment as noted above, losses through bereavement or rupture of relationships with family members and other sources of support. Serious relationship and financial problems distinguished older adult suicides and near fatal suicide attempters from controls in New Zealand (20), findings replicated by Rubenowitz and colleagues in Sweden (16). Our group also has reported that family discord and employment change distinguished suicides from controls over the age of 50 years even after adjusting for socio-demographic characteristics and mental disorders (18).

On both theoretical and empirical bases, the construct of "social connectedness" may be especially important when understanding late life suicide and its prevention. Indeed, the Centers for Disease Control has identified as a key strategy for preventing suicidal behavior at all ages "the promotion and strengthening of connectedness at personal, family, and community levels" (39). Holt-Lunstad and colleagues in a recent meta-analytic review of 148 studies to determine the extent to which social relationships influence risk for mortality (40). They found that overall there was a 50 percent increased likelihood of survival for participants with stronger social relationships. Furthermore, they noted that the influence of a social connectedness on risk for death is comparable to or greater than that associated with well-established risk factors such as smoking, obesity, and physical inactivity. The authors excluded studies in which suicide was included as a cause of death; however, other evidence strongly supports this link as well. PA studies have shown that older adult suicides were significantly less likely to have had a confidante (41), more likely to live alone than their peers in the community (7), and less likely to participate in community activities (19), be active in organizations, or have a hobby (16). Also, Turvey and colleagues found in analyses of data from a prospective cohort study that having a greater number of friends and relatives in whom to confide was associated with significantly reduced suicide risk in older adults (42).

The Interpersonal Theory of Suicide articulated by Joiner and colleagues offers one way of understanding the relationship of social connectedness with suicide (43). It proposes that there are two proximal causes of the desire for suicide -- thwarted belongingness and perceived burdensomeness -- with a particularly dangerous level of suicidal desire resulting from the simultaneous presence of both factors. In the presence of an acquired capability for suicide (e.g., prior experience with pain or well developed cognitive models of one's death) these painful psychological states may become lethal. The construct of thwarted belongingness stems from the fundamental need for connectedness posited by Baumeister and Leary as the "need to belong (44), reflected in indices of social isolation that have been empirically linked with late life suicide such as living alone, loss of spouse, loneliness, and low social support. Perceived burdensomeness is a construct less fully explored in research, but a common theme heard by clinicians who work with older adults whom they perceive to be at risk. The theory proposes that both family discord and functional impairments are associated with late life suicide because both factors are likely to engender perceptions of 
burdensomeness on others. Conversely, connections to other individuals and to his or her community may serve to protect the older person against the development of suicidal desire in the face of stressful life circumstances. However, according to the theory, only connections that contribute to individuals' need to belong-connections that create positive interactions and feelings of being cared about — will be protective. Thus, relationships characterized by perceived burdensomeness, or other forms of interpersonal discord, will not protect against suicide. Spirituality and religiousness have been cited as protective factors against the development of the depression and suicidality $(19,45)$, a relationship that might also be understood as a function of connectedness at a spiritual or instrumental level (e.g., support provided to an isolated elder by their faith community.) As well, differences in suicide risk as a function of gender and race/ethnicity with aging might be understood in part by the stronger ties to supportive others that woman and some minority communities have capacity to establish relative to men and white race groups in general (46). The Interpersonal Theory proposes that risk factors for suicide, including psychiatric illness, elevate risk for suicide by causing or exacerbating thwarted belongingness, perceived burdensomeness and/ or acquired capability. Future research should empirically examine this hypothesis.

\section{Other factors}

Risk factors in psychiatric, physical and functional, and social domains operate in complex interactions against a background colored by one's culture, personality traits, and even neurobiological make up. Suicidal elders have been characterized as timid and seclusive (47), hostile, rigid and with an independent style $(47,48)$. Based on standardized measures and case controlled PA methodology, anankastic (obsessional) and anxious traits were shown to significantly distinguish suicides from elder natural death controls in one study (12), while in another, the "Big Five" personality traits of low Openness to Experience (OTE) and high Neuroticism (49) distinguished the groups (50). Low OTE is associated with muted affective and hedonic responses, a constricted range of interests, and a strong preference for the familiar over the novel. Duberstein and colleagues hypothesize that older adults low in OTE are at risk for suicide because they are less well equipped socially and psychologically to manage the challenges of aging, and less likely to be recognized as being in distress and need of intervention (51) - another manifestation of poor social connectedness.

Numerous reports of associations between suicidal behavior and a range of neurobiological parameters have emerged from studies of mixed age and younger adult samples (52). They raise the exciting prospect that genetically mediated abnormalities in central nervous system processes predispose individuals to act impulsively and aggressively in the face of dysphoria, hopelessness, and emergent suicidal ideation in the depressed state. Furthermore, they suggest a possibility that age-related changes in these systems may further account for the rise in suicide rates in later life, particularly if these differences were shown to be more pronounced in men than women. However, few studies have examined neurobiological systems in suicidal older adults because high rates of medication use and medical comorbidity in older adult suicides and attempted suicides complicate interpretation and findings in such studies. Additional research is necessary on the role of neurobiological factors in late life suicide, just as it is for factors in other domains and, perhaps most importantly, their interaction in determining risk.

\section{Developmental Trajectories}

Knowledge of factors that increase or decrease risk for suicide in older adults is necessary but not sufficient for the effective design of preventive interventions. It is insufficient because they are so inefficient, either individually or in combinations, for predicting outcomes for any individual. The large number of "false positives" that resulted from their 
widespread use would lead to unnecessary, intrusive, and expensive interventions for those who did not need them, while many "false negatives" results would leave at-risk elders undetected and unprotected. The limitations of risk and protective factors as tools to predict and prevent suicide are related in part to the fact that risk states are dynamic -- they wax and wane over short periods of time. Suicide therefore, is better understood as a developmental process that evolves over longer periods. Figure 3 attempts to capture that process and relate it to a public health framework for prevention. The " $x$ axis" represents the dimension of time. On a foundation of personality characteristics, individual neurobiological factors, and cultural context, each older person encounters stressful events. In the struggle with acute and chronic medical illnesses and functional decline, some become socially disconnected. Relative risk increases among those who are less resilient and develop early symptoms of psychiatric illness. Some become more frankly depressed and hopeless, the most vulnerable of whom enter the peri-suicidal state. Risks mount over time with the accumulation of progressively more proximal risk factors and/or the loss of protective buffers. Those with active ideation and capability of taking their own lives act on their suicidal desire, and many die.

The notion that suicidal processes unfold over time has important implications for prevention. While it connotes a level of complexity that is on one hand daunting, it also indicates opportunities to intervene at multiple points and in many different ways. We now turn attention to considering those opportunities for intervention.

\section{Approaches to Prevention}

A medical model or "high risk" approach to suicide prevention would tend to focus on that terminal segment of the developmental process at the right of the diagram in Figure 3 when older adults were at greatest risk. A public health approach would see opportunities for preventive intervention across the entire continuum. Indeed, it would propose that interventions targeting more distal and intermediate factors and stages of the process may result in more lives saved than those restricting focus to higher risk individuals $(53,54)$. This premise may apply more directly to older adults than younger age groups because suicidal behavior in elders is so much more lethal. Studies estimate that as many as 200 young adults attempt suicide for each one that dies by his own hand (55). Among older adults attempts are far less common, yielding a ratio of perhaps four attempts per completed suicide (56). Whether due to elders' increased isolation and decreased chances of rescue, their greater frailty and hence likelihood of dying as a result of any self-inflicted injury, or the older population's tendency to use more immediately lethal means with greater planning and determination (57), the implications are clear: interventions to prevent the development of the suicidal state are especially critical in this age group.

The Institute of Medicine has advocated use of terminology describing preventive interventions at three levels: indicated, selective, and universal (58). Table 3 provides definitions and examples of each.

Indicated preventive interventions are those that target individuals who have detectable symptoms and other proximal risk factors for suicide. Their objective is typically to diagnose and treat psychiatric disorder in order to prevent the expression of suicidal behavior. The sites in which indicated preventive interventions are typically mounted include primary care and specialty mental health settings. Because older adults are reluctant to seek care in mental health clinics or providers' offices, however, interventions delivered in primary care are likely to be more effective (59).

Effective diagnosis and treatment of depression is most often cited as an example of indicated preventive intervention because of the close association between affective illness 
and suicide in older people. Several lines of evidence reinforce the importance of this approach. In 2009 Stone and colleagues published an analysis of proprietary data submitted to the US Food and Drug Administration (FDA) from 372 double blind randomized placebo controlled trials of antidepressants in adults (60). The analysis was driven by concern that antidepressant administration may in fact exacerbate suicide risk among some patients. They found that the relative risk for suicidal ideation or behavior emerging during antidepressant treatment was indeed elevated for participants under age 25, no different than placebo for those aged $25-64$, and significantly reduced for those over age 65 who received antidepressant treatment.

However, affective illness often goes undetected and inadequately treated in primary care settings. Two groups therefore conducted randomized trials in which elderly primary care patients were randomized to receive either care-as-usual or a collaborative, stepped-care intervention in which mental health expertise, physician and patient/family education about depression, use of treatment algorithms and decision support tools were provided (61)(62). Although there were differences in the details of each intervention (e.g., the antidepressants and psychosocial interventions offered), both studies found significantly greater reductions in depressive symptoms and suicidal ideation in depressed older adults who received the experimental interventions $(63,64)$. Due to sample size limitations, neither trial could assess the effectiveness of the intervention on suicidal behavior, however, and the relatively high proportions of female subjects leaves open the question of how effective they would be in reducing attempted and completed suicide among those at greatest risk in later life, men.

Selective preventive interventions target asymptomatic or pre-symptomatic individuals or groups with more distal risk factors, as depicted in middle and on the left side of Figure 3. They may include, for example, older people with chronic, painful, functionally limiting conditions or those who have become socially isolated or perceive themselves to be a burden on others. The sites at which one might most effectively and efficiently engage older adults in selective preventive interventions are, therefore, broader than for indicated interventions. They could include, for example, the homes of older people receiving visiting nurse or aide services or home-delivered meals; or in agencies that provide community-based social services. Examples of selective preventive interventions for suicide are rare, although we posit that trials designed to prevent incident depression among elders at increased risk for the disorder would achieve the same end. The Telehelp/Telecheck service reported by DeLeo and colleagues represents a rare example of selective prevention in which completed suicide in older adults was the targeted outcome (65). Based in Padua, Italy, the Telehelp/ Telecheck service provided telephone-based outreach, evaluation, and support services to more than 18,000 seniors with a mean age of 80 years. Over 84 percent were women. During the service's 11 year in operation there were significantly fewer suicides among its clients than were anticipated in the elder population of that region. Further analyses found the effect was only significant for women, possibly because of the small numbers of men enrolled in the program and/or their resistance to a social outreach intervention of this nature.

Finally, universal preventive interventions target an entire population irrespective of the risk status of any individual or group within it. The sites therefore for universal prevention are ones that allow broad dissemination of public health messages, or via legislative policy forums to effect change in levels of exposure across the population.

Although there are no randomized controlled trials of universal prevention of suicide, ecological studies and "natural experiments" offer some support for their effectiveness in later life. Hawton and colleagues reported that after legislation was implemented to limited the pack size of paracetamol and salicylates sold over the counter in the United Kingdom, 
morbidity and mortality from overdose with those medications decreased significantly (66). Another example in the U.S. was afforded by passage of the Brady Handgun Violence Prevention Act in 1994. Ludwig and Cooke observed that in the years following implementation of the legislation there was a significantly greater reduction suicides with a handgun by people over the age of 55 years in those states that newly implemented background checks and waiting periods for gun purchase than states in which no changes in procedures were necessary (67).

Because universal, selective, and indicated prevention target the suicidal process at different levels, it is likely that the most effective prevention program for suicide in later life would be one that incorporates elements of each. The best example of a multi-faceted prevention program of which we are aware is a series of five quasi-experimental studies combined in an meta-analysis by Oyama and colleagues (68). Although the details differed somewhat between studies, each was conducted in a different Japanese rural region with high suicide rates among older people (greater than 160 per 100,000). Implemented over 5 - 10 year periods, the interventions included systematic community-wide screening, referral to primary care or mental health care as indicated, and, to varying degrees, public education and socialization programs for seniors. The authors examined changes in the relative risk or incidence risk ratios for suicide in older adults before and after the programs' implementation and relative to neighboring reference regions of similar size and character. Overall, risk was significantly reduced in men and women when follow-up was conducted by a psychiatrist, but only in women when follow-up was conducted by general practitioners. Again, older men proved relatively more resistant to the effects of preventive intervention.

\section{Summary}

Anticipated rapid increases in the size of the older adult population, fueled by aging of the baby boom cohort that life-long has carried a greater propensity to suicide than earlier or later birth cohorts, require urgent attention and allocation of resources to the development and study of approaches to suicide prevention best tailored to older adults. Informed by our knowledge of risk and protective factors, models for how those factors work variably and through complex interactions over time to place vulnerable seniors at risk form the basis for that work.

The importance of depression as a pathogenetic factor in late life suicide makes its detection and effective treatment of paramount importance. Collaborative care delivered by primary care providers informed by mental health expertise has shown promise as an indicated preventive intervention, although its effect in reducing suicide among elderly men remains to be determined. Results of Oyama's meta-analysis cast additional doubt on whether primary care intervention alone will be sufficient, at least for elderly men, who are by far the highest risk group in the U.S. Incorporation of additional selective prevention approaches targeting the older adults in a range of community settings should be further developed and tested as a component of any community's comprehensive late life suicide prevention plan, with special emphasis on maintaining their connectedness to families, friends, and communities. Finally, consideration must be given to universal preventive approaches such as restricting access to highly lethal means by at-risk elders and changing attitudes and biases that inhibit older adults from accessing effective and affordable mental health care.

\section{Acknowledgments}

Funding support: This work was supported in part by Grant No. T32 MH20061 from the National Institute of Mental Health. 


\section{References}

1. Centers for Disease Control and Prevention. WISQARS: Web-based Injury Statistics Query and Reporting System. http://www.cdc.gov/ncipc/wisqars/default.htm

2. World Health Organization - Mental Health. Suicide prevention (SUPRE). http://www.who.int/mental_health/prevention/suicide/suicideprevent/en/

3. Centers for Disease Control and Prevention, The Merck Company Foundation. Witehouse Station, NJ: 2007. The State of Aging and Health in America. www.cdc.gov/aging

4. Hawton K, Appleby L, Platt S, Foster T, Cooper J, Malmberg A, et al. The psychological autopsy approach to studying suicide: a review of methodological issues. J Affect Disord. 1998; 50(2-3): 269-276. [PubMed: 9858086]

5. Conner KR, Conwell Y, Duberstein PR. The validity of proxy-based data in suicide research: a study of patients 50 years of age and older who attempted suicide. II. Life events, social support and suicidal behavior. Acta Psychiatr Scand. 2001; 104(6):452-457. [PubMed: 11782238]

6. Conner KR, Duberstein PR, Conwell Y. The validity of proxy-based data in suicide research: a study of patients 50 years of age and older who attempted suicide. I. Psychiatric diagnoses. Acta Psychiatr Scand. 2001; 104(3):204-209. [PubMed: 11531657]

7. Barraclough BM. Suicide in the elderly: recent developments in psychogeriatrics. Br J Psychiatry. 1971 Spec. Suppl. \#6:87-97. [PubMed: 5576272]

8. Carney SS, Rich CL, Burke PA, Fowler RC. Suicide over 60: the San Diego study. J Am Geriatr Soc. 1994; 42(2):174-180. [PubMed: 8126332]

9. Chiu HF, Yip PS, Chi I, Chan S, Tsoh J, Kwan CW, et al. Elderly suicide in Hong Kong--a casecontrolled psychological autopsy study. Acta Psychiatr Scand. 2004; 109(4):299-305. [PubMed: 15008804]

10. Clark DC. Suicide among the elderly. Final report to the AARP Andrus Foundation. 1991

11. Conwell Y, Duberstein PR, Cox C, Herrmann JH, Forbes NT, Caine ED. Relationships of age and axis I diagnoses in victims of completed suicide: a psychological autopsy study. Am J Psychiatry. 1996; 153(8):1001-1008. [PubMed: 8678167]

12. Harwood D, Hawton K, Hope T, Jacoby R. Psychiatric disorder and personality factors associated with suicide in older people: a descriptive and case-control study. Int J Geriatr Psychiatry. 2001; 16(2):155-165. [PubMed: 11241720]

13. Henriksson MM, Marttunen MJ, Isometsa ET, Heikkinen ME, Aro HM, Kuoppasalmi KI, et al. Mental disorders in elderly suicide. Int Psychogeriatrics. 1995; 7(2):275-286.

14. McGirr A, Renaud J, Bureau A, Seguin M, Lesage A, Turecki G. Impulsive-aggressive behaviours and completed suicide across the life cycle: a predisposition for younger age of suicide. Psychol Med. 2008; 38(3):407-17. [PubMed: 17803833]

15. Waern M, Runeson BS, Allebeck P, Beskow J, Rubenowitz E, Skoog I, et al. Mental disorder in elderly suicides: a case-control study. Am J Psychiatry. 2002; 159(3):450-5. [PubMed: 11870010]

16. Rubenowitz E, Waern M, Wilhelmson K, Allebeck P. Life events and psychosocial factors in elderly suicides--a case-control study. Psychol Med. 2001; 31(7):1193-202. [PubMed: 11681545]

17. Britton PC, Duberstein PR, Conner KR, Heisel MJ, Hirsch JK, Conwell Y. Reasons for living, hopelessness, and suicide ideation among depressed adults 50 years or older. Am J Geriatr Psychiatry. 2008; 16(9):736-41. [PubMed: 18757767]

18. Duberstein PR, Conwell Y, Conner KR, Eberly S, Caine ED. Suicide at 50 years of age and older: perceived physical illness, family discord and financial strain. Psychol Med. 2004; 34(1):137-146. [PubMed: 14971634]

19. Duberstein PR, Conwell Y, Conner KR, Eberly S, Evinger JS, Caine ED. Poor social integration and suicide: fact or artifact? A case-control study. Psychol Med. 2004; 34(7):1331-1337. [PubMed: 15697059]

20. Beautrais AL. A case control study of suicide and attempted suicide in older adults. Suicide LifeThreat Behav. 2002; 32(1):1-9. [PubMed: 11931007]

21. Conwell Y, Duberstein PR, Hirsch JK, Conner KR, Eberly S, Caine ED. Health status and suicide in the second half of life. Int J Geriatr Psychiatry. 2009; 25(4):371-9. [PubMed: 19582758] 
22. Erlangsen A, Zarit SH, Conwell Y. Hospital-diagnosed dementia and suicide: a longitudinal study using prospective, nationwide register data. Am J Geriatr Psychiatry. 2008; 16(3):220-8. [PubMed: 18310552]

23. Haw C, Harwood D, Hawton K. Dementia and suicidal behavior: a review of the literature. Int Psychogeriatr. 2009; 21(3):440-53. [PubMed: 19368760]

24. Rubio A, Vestner AL, Stewart JM, Forbes NT, Conwell Y, Cox C. Suicide and Alzheimer's pathology in the elderly: a case-control study. Biol Psychiatry. 2001; 49(2):137-145. [PubMed: 11164760]

25. Harris EC, Barraclough BM. Suicide as an outcome for medical disorders. Medicine (Baltimore). 1994; 73(6):281-296. [PubMed: 7984079]

26. Juurlink DN, Herrmann N, Szalai JP, Kopp A, Redelmeier DA. Medical illness and the risk of suicide in the elderly. Arch Intern Med. 2004; 164(11):1179-1184. [PubMed: 15197042]

27. Quan H, Arboleda-Florez J, Fick GH, Stuart HL, Love EJ. Association between physical illness and suicide among the elderly. Soc Psychiatry Psychiatr Epi. 2002; 37(4):190-197.

28. Conwell Y, Caine ED, Olsen K. Suicide and cancer in late life. Hosp Commun Psychiatry. 1990; 41(12):1334-1339.

29. Kaplan G, Barell V, Lusky A. Subjective state of health and survival in elderly adults. J Gerontology. 1988; 43(4):S114-20.

30. Sirey JA, Bruce ML, Carpenter M, Booker D, Reid MC, Newell KA, et al. Depressive symptoms and suicidal ideation among older adults receiving home delivered meals. Int J Geriatr Psychiatry. 2008; 23(12):1306-11. [PubMed: 18615448]

31. Li L, Conwell Y. Pain and self-injury ideaion in elderly men and women receiving home care. J Am Geriatr Soc. in press.

32. Dombrovski AY, Butters MA, Reynolds CF 3rd, Houck PR, Clark L, Mazumdar S, et al. Cognitive performance in suicidal depressed elderly: preliminary report. Am J Geriatr Psychiatry. 2008; 16(2):109-15. [PubMed: 18239196]

33. Keilp JG, Sackeim HA, Brodsky BS, Oquendo MA, Malone KM, Mann JJ. Neuropsychological dysfunction in depressed suicide attempters. Am J Psychiatry. 2001; 158(5):735-741. [PubMed: 11329395]

34. King DA, Conwell Y, Cox C, Henderson RE, Denning DG, Caine ED. A neuropsychological comparison of depressed suicide attempters and nonattempters. J Neuropsychiatry Clin Neurosci. 2000; 12(1):64-70. [PubMed: 10678515]

35. Dombrovski AY, Clark L, Siegle GJ, Butters MA, Ichikawa N, Sahakian BJ, et al. Reward/ Punishment reversal learning in older suicide attempters. Am J Psychiatry. 2010; 167(6):699-707. [PubMed: 20231320]

36. Arango V, Underwood MD, Mann JJ. Postmortem findings in suicide victims. Implications for in vivo imaging studies. Ann N Y Acad Sci. 1997; 836:269-87. [PubMed: 9616804]

37. Ahearn EP, Jamison KR, Steffens DC, Cassidy F, Provenzale JM, Lehman A, et al. MRI correlates of suicide attempt history in unipolar depression. Biol Psychiatry. 2001; 50:266-270. [PubMed: 11522261]

38. Alexopoulos GS, Meyers BS, Young RC, Campbell S, Silbersweig D, Charlson M. 'Vascular depression' hypothesis. Arch Gen Psychiatry. 1997; 54(10):915-922. [PubMed: 9337771]

39. Centers for Disease Control and Prevention. Connectedness as a strategic direction for the prevention of suicidal behavior: Promoting individual, family, and community connectedness to prevent suicidal behavior. 2006. http://www.cdc.gov/violenceprevention/pdf/Suicide_Strategic_Direction_Full_Version-a.pdf

40. Holt-Lunstad J, Smith TB, Layton JB. Social Relationships and Mortality Risk: A Meta-analytic Review. PLoS Med. 2010; 7(7):e1000316. [PubMed: 20668659]

41. Miller M. A psychological autopsy of a geriatric suicide. J Geriatr Psychiatry. 1977; 10(2):229_ 242. [PubMed: 608940]

42. Turvey CL, Conwell Y, Jones MP, Phillips C, Simonsick E, Pearson JL, et al. Risk factors for latelife suicide: a prospective, community-based study. Am J Geriatr Psychiatry. 2002; 10(4):398406. [PubMed: 12095899] 
43. Van Orden KA, Witte TK, Cukrowicz KC, Braithwaite SR, Selby EA, Joiner TE Jr. The interpersonal theory of suicide. Psychol Rev. 2010; 117(2):575-600. [PubMed: 20438238]

44. Baumeister RF, Leary MR. The need to belong: desire for interpersonal attachments as a fundamental human motivation. Psychol Bull. 1995; 117(3):497-529. [PubMed: 7777651]

45. Dervic K, Oquendo MA, Grunebaum MF, Ellis S, Burke AK, Mann JJ. Religious Affiliation and Suicide Attempt. Am J Psychiatry. 2004; 161(12):2303-2308. [PubMed: 15569904]

46. Institute of M. Goldsmith, SK.; Pellmar, TC.; Kleinman, AM.; Bunney, WE. Reducing Suicide: A National Imperative. Washington, D.C.: The National Academies Press; 2002.

47. Batchelor IRC, Napier MB. Attempted suicide in old age. BMJ. 1953; 2:1186-1190. [PubMed: 13106375]

48. Clark DC. Narcissistic crises of aging and suicidal despair. Suic Life-Threat Behav. 1993; 23(1): 21-26.

49. Costa, PT.; McCrae, RR. Revised NEO Personality Inventory and NEO Five Factor Inventory: Professional Manual. Odessa, FL: PAR; 1992.

50. Duberstein PR. Openness to experience and completed suicide across the second half of life. Int Psychogeriatrics. 1995; 7(2):183-198.

51. Duberstein PR. Are closed-minded people more open to the idea of killing themselves? Suic LifeThreat Behav. 2001; 31(1):9-14.

52. Mann JJ, Waternaux C, Haas GL, Malone KM. Toward a clinical model of suicidal behavior in psychiatric patients. Am J Psychiatry. 1999; 156(2):181-189. [PubMed: 9989552]

53. Rose, G. The strategy of preventive medicine. Oxford: Oxford University Press; 1992.

54. Knox KL, Conwell Y, Caine ED. If suicide is a public health problem, what are we doing to prevent it? Am J Public Health. 2004; 94(1):37-45. [PubMed: 14713694]

55. Fremouw, WJ.; dePerczel, M.; Ellis, TE. Suicide Risk: Assessment and Response Guidelines. New York: Pergamon Press; 1990.

56. McIntosh, JL.; Santos, JF.; Hubbard, RW.; Overholser, JC. Elder Suicide: Research, Theory, and Treatment. Washington, D.C.: American Psychological Association; 1994.

57. Conwell Y, Duberstein PR, Cox C, Herrmann J, Forbes N, Caine ED. Age differences in behaviors leading to completed suicide. Am J Geriatr Psychiatry. 1998; 6(2):122-126. [PubMed: 9581207]

58. Institute of M. Mrazek, PJ.; Haggerty, RJ. Reducing Risks for Mental Disorders: Frontiers for Preventive Intervention Research. Washington, D.C.: National Academy Press; 1994.

59. Bartels SJ, Coakley EH, Zubritsky C, Ware JH, Miles KM, Arean PA, et al. Improving Access to Geriatric Mental Health Services: A Randomized Trial Comparing Treatment Engagement With Integrated Versus Enhanced Referral Care for Depression, Anxiety, and At-Risk Alcohol Use. Am J Psychiatry. 2004; 161(8):1455-1462. [PubMed: 15285973]

60. Stone M, Laughren T, Jones ML, Levenson M, Holland PC, Hughes A, et al. Risk of suicidality in clinical trials of antidepressants in adults: analysis of proprietary data submitted to US Food and Drug Administration. BMJ. 2009; 339(aug11_2):b2880. [PubMed: 19671933]

61. Bruce ML, Ten Have T, Reynolds CF III, Katz IR, Schulberg HC, Mulsant BH, et al. Reducing Suicidal Ideation and Depressive Symptoms in Depressed Older Primary Care Patients: A Randomized Controlled Trial. JAMA. 2004; 291(9):1081-1091. [PubMed: 14996777]

62. Unutzer J, Katon W, Callahan CM, Williams JW Jr, Hunkeler E, Harpole L, et al. Collaborative care management of late-life depression in the primary care setting: a randomized controlled trial. JAMA. 2002; 288(22):2836-2845. [PubMed: 12472325]

63. Alexopoulos GS, Reynolds CFI, Bruce ML, Katz IR, Raue PJ, Mulsant BH, et al. Reducing suicidal ideation and depression in older primary care patients: 24-month outcomes of the PROSPECT Study. Am J Psychiatry. 2009; 166:882-890. [PubMed: 19528195]

64. Unutzer J, Tang L, Oishi S, Katon W, Williams JW Jr, Hunkeler E, et al. Reducing suicidal ideation in depressed older primary care patients. J Am Geriatr Society. 2006; 54(10):1550-1556.

65. De Leo D, Dello Buono M, Dwyer J. Suicide among the elderly: the long-term impact of a telephone support and assessment intervention in northern Italy. Br J Psychiatry. 2002; 181:226229. [PubMed: 12204927] 
66. Hawton K, Townsend E, Deeks J, Appleby L, Gunnell D, Bennewith O, et al. Effects of legislation restricting pack sizes of paracetamol and salicylate on self poisoning in the United Kingdom: before and after study. BMJ. 2001; 322(7296):1203-1207. [PubMed: 11358770]

67. Ludwig J, Cook PJ. Homicide and suicide rates associated with implementation of the Brady Handgun Violence Prevention Act. JAMA. 2000; 284(5):585-591. [PubMed: 10918704]

68. Oyama H, Sakashita T, Ono Y, Goto M, Fujita M, Koida J. Effect of community-based intervention using depression screening on elderly suicide risk: a meta-analysis of the evidence from Japan. Comm Ment Health J. 2008; 44(5):311-20. 


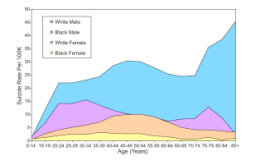

Figure 1. Suicide rates by age, race, and gender in the United States, 2007 (From the Centers for Disease Control and Prevention, 2010) 


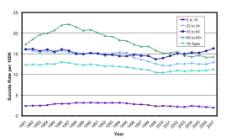

Figure 2. 1981-2007, United States suicide rates per 100,000, all races, both sexes (From the Centers for Disease Control and Prevention, 2010) 


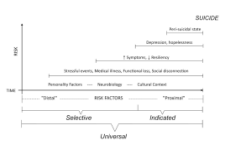

Figure 3. The developmental model of late life suicide 


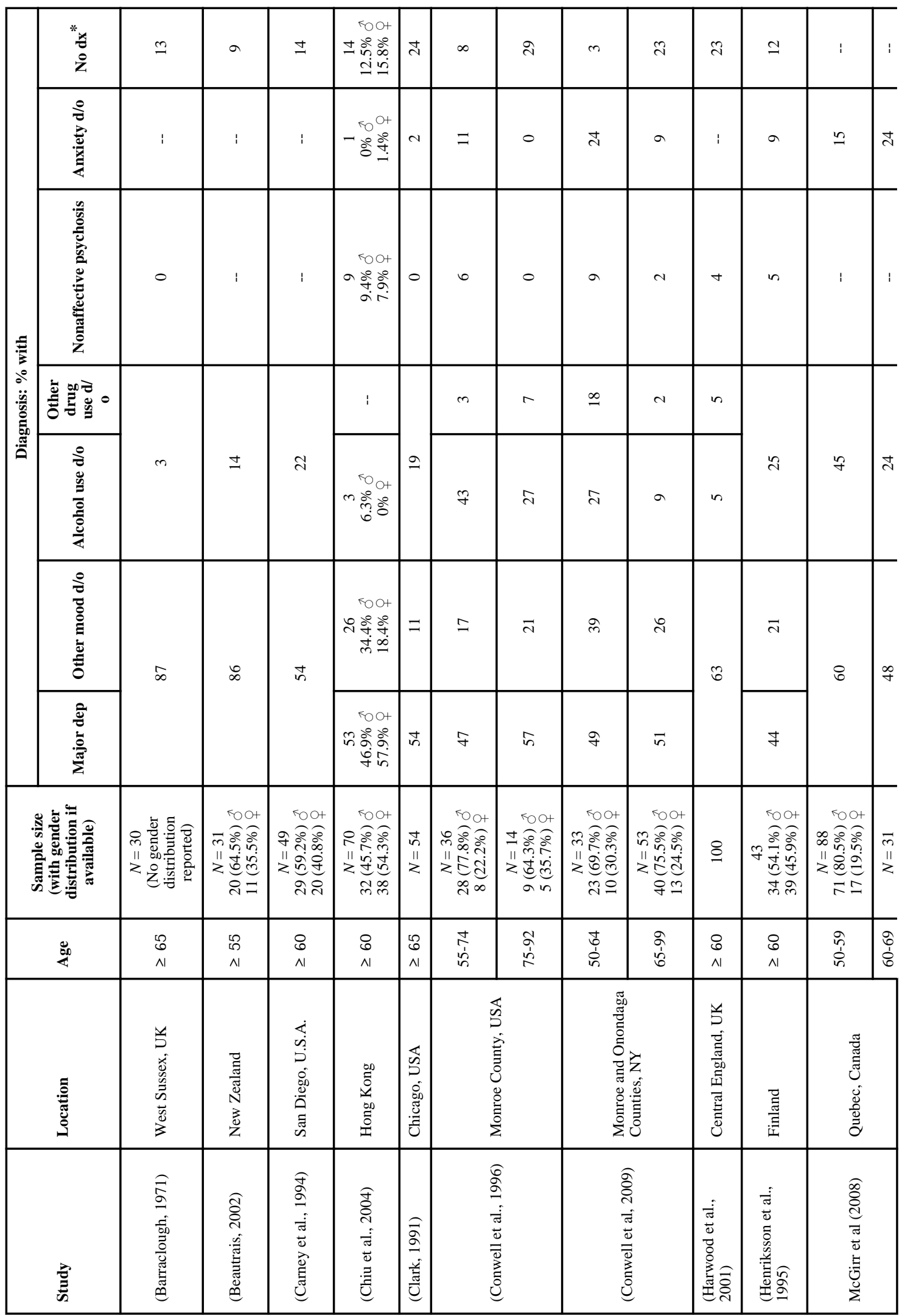

Psychiatr Clin North Am. Author manuscript; available in PMC 2012 June 1. 


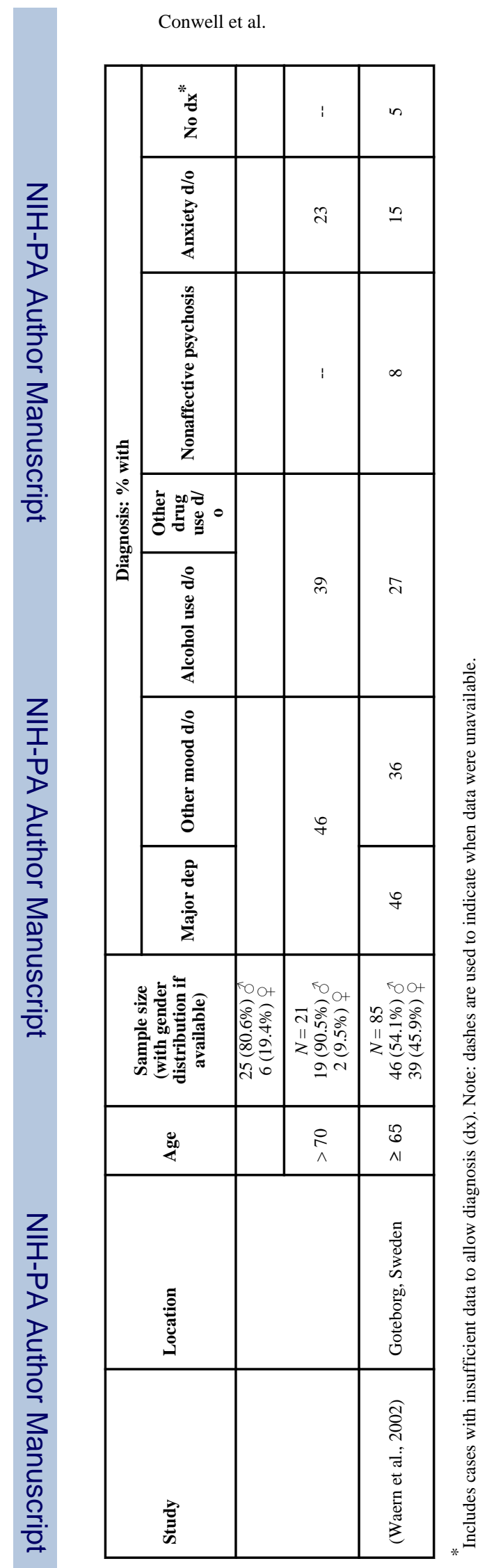

Psychiatr Clin North Am. Author manuscript; available in PMC 2012 June 1. 


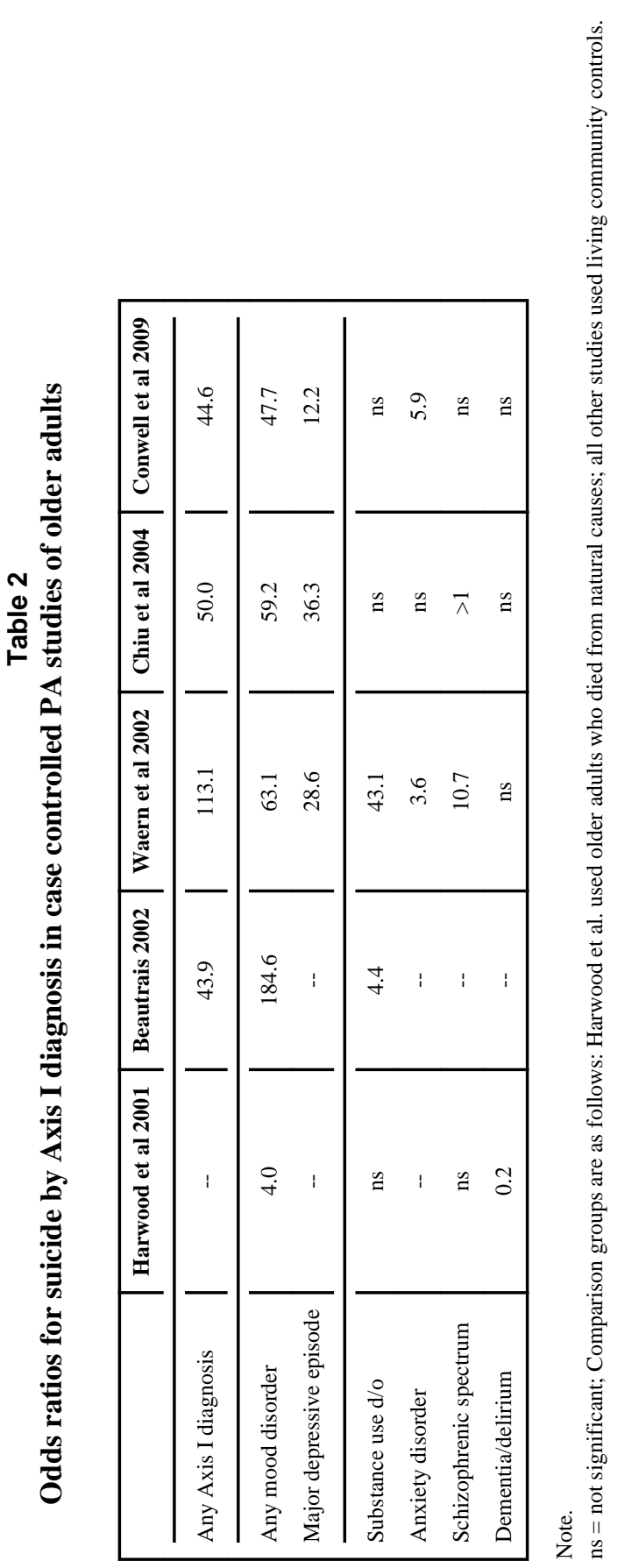

Psychiatr Clin North Am. Author manuscript; available in PMC 2012 June 1. 


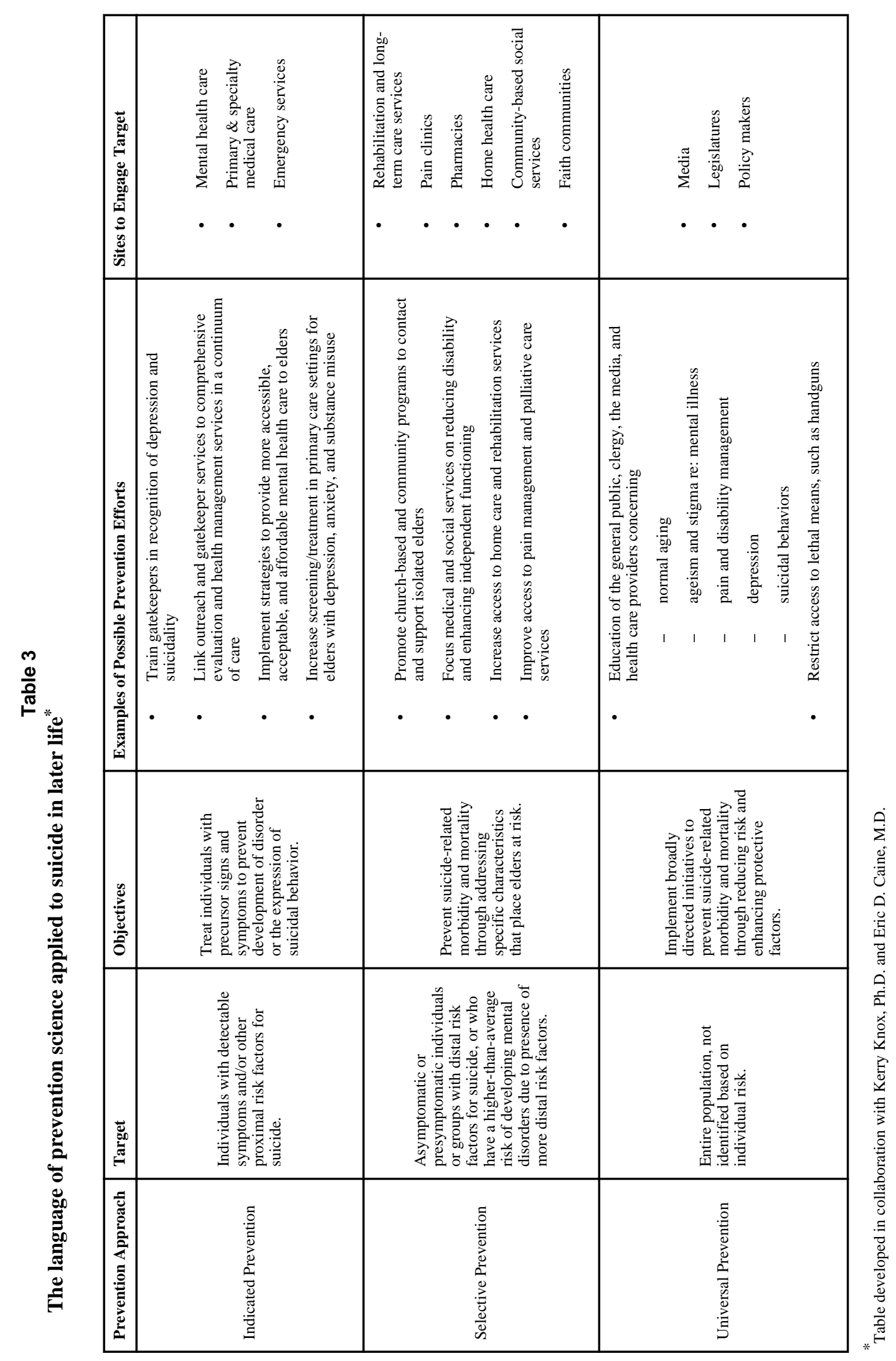

Psychiatr Clin North Am. Author manuscript; available in PMC 2012 June 1. 